\title{
An overview of audiovisual translation: Four methodological turns in a mature discipline
}

Frederic Chaume

Universitat Jaume I

Citation: Chaume, F. (2018). An overview of audiovisual translation:

Four methodological turns in a mature discipline. Journal of Audiovisual Translation, 1(1), 40-63.

Editor: A. Jankowska \& J. Pedersen

Received: September 1, 2018

Accepted: September 30, 2018

Published: November 15, 2018

Copyright: @2018 Chaume. This is an open access article distributed under the terms of the Creative Commons Attribution License. This allows for unrestricted use, distribution, and reproduction in any medium, provided the original author and source are credited.

\section{Abstract}

Digital technology has played a crucial role not only in the process of production and distribution of audiovisual content, but also in the process of localization and consumption of audiovisual products. This has had an obvious impact on audiovisual translation as a field, both in professional circles as well as in scholarly research. To date, this field of research has grown exponentially, parallel to the production, consumption, interaction with and general interest in audiovisual products. At the same time, translation studies have been growing as a discipline and, consequently, has been influencing audiovisual translation (AVT) research. This article presents a due brief overview of the four turns audiovisual translation has taken to date (the descriptive, the cultural, the sociological and the cognitive turns), and identifies some of the major steps already undertaken, as well as possible research avenues that such turns are currently opening.

Key words: audiovisual translation, descriptive studies, cognitive studies, cultural studies, sociological studies, funsubs, fundubs, literal dub versions, honest subtitles.

凶chaume@uji.es; https://orcid.org/0000-0002-4843-5228 


\section{The coming of age of a discipline: four methodological paradigms}

Following the first monograph in audiovisual translation (Laks, 1957), sixty years ago, and the first specialised issue of a journal devoted partially to this field (Babel, 1960); and following the first research works, dating back approximately thirty to forty years (Brant, 1984; Delabastita, 1989; Fodor, 1976; Gautier, 1981; Hendrickx, 1984; Herbst, 1987; Hochel, 1986; Mason, 1989; Mayoral, Kelly \& Gallardo, 1986; Pommier, 1988; Titford, 1982; Vöge, 1977 among others), it can be said that AVT has certainly gained the right to constitute a legitimate and independent field of studies, matching the status of any other area of studies in translation and interpreting (Carbonell, 2018; Díaz Cintas, 2004a, 2009).

This statement does not come unjustified. Although, epistemologically speaking, it is difficult to define a clear border between audiovisual translation studies and translation studies, or even interpreting studies (with which AVT has many common threads, and not only in the case of respeaking), audiovisual translation has undoubtedly boomed in all respects. This phenomenon has kindled the interest of many academics and researchers, enticing numerous theoretical, descriptive, sociological and experimental studies.

The reason behind this is the exponential increase in today's active and passive consumption of audiovisual products, when compared to previous decades (Pérez-González, 2014). The global world media markets that produce audiovisual content and entertainment are absolutely aware of this and consequently, are becoming ever more aware of the role of translation, also referred to by the industry as localization, internationalization or even glocalization, that is, the process of adapting an audiovisual production to the norms, likes and dislikes of different target cultures.

Digital technology has played a crucial role not only in the process of production and distribution of audiovisual content, but as far as our interest goes, in the process of localization and consumption of audiovisual products. It has been the primary cause for the current blooming of new forms of elaboration and consumption of audiovisual products, for the optimized use of new devices (laptops, tablets, smartphones) and also for new forms of communication (social networks, crowdsourcing). Consequently, technological developments have brought about new audiovisual transfer modes, or new combinations of the latter.

This has had an obvious impact on audiovisual translation as a field, both in professional circles as well as in scholarly research. To date, this field of research has grown exponentially, parallel to the production, consumption, interaction with and general interest in audiovisual products. Scholarly research was initially driven by the urge to identify the distinctive traits of audiovisual translation. It identified features of the source text (ST) that could potentially constitute translation issues, a good part of which (mainly audiovisual translation constraints) differed from the more conventional issues belonging to literary translation, legal translation, and other types of written 
translation. This first stage also included a preliminary analysis and description of the translation process in the market, the roles of the agents involved, and the translator's task.

This first (and necessary stage) came to an end in the turn of the century when descriptive translation studies (DTS) picked up the baton of academic research, and soon after, scholars focused their attention on the target text (TT), the translated text, applying functionalist theories and/or descriptive methodologies. This constituted the first turn of this discipline.

Cultural approaches were easily drawn from DTS. Most of them, however, tend to be particular studies focused on the major issues of the Cultural Turn: the concepts of ideology, otherness, postcolonialism, power, resistance, patronage and censorship, bringing to the fore issues of identity, gender stereotypes, race, etc. Contrary to usual DTS analysis in AVT, cultural studies have gone beyond the explanations for the translation patterns found in descriptive research. Cultural approaches put into question the recurrent use of some allegedly innocent strategies and reveal their intentional and deliberate choices. Although some of this cultural research is based on the foundations of prior descriptive studies, the change of focus constitutes another major turn in our discipline.

Scholarly research subsequently shifted interest from the translated text to the agents involved in the translation of the audiovisual text, but this time, adopting a social approach, hence taking a step further from the nineties. Thanks to this social and sociological turn (Wolf \& Fukari, 2007), grounded mainly in Bourdieu's sociological paradigm, audiovisual translation research started to investigate the role of the translator and the powers mediating in the selection, translation and adaptation of an audiovisual text, as well as the new active role of audiences, which are now producing new types of translations, from heterofunctional gag translations to activist translations, for example, in the case of honest subtitling. This has constituted the third turn in AVT research.

Last, a cognitive and empirical turn is also gaining ground in academia. Since the first and pioneering reception studies in Audiovisual Translation, mainly carried out in Italy, Poland and Spain at the turn of the century, the use of technology has constituted a step forward in experimental research methods, and now the interest is geared not only towards the translator's mental processes, as it was in the nineties with the first experimental research in Think Aloud Protocols, but also, and mainly, on the audience's response to audiovisual translation. This is done with the aid of eyetrackers and biometric sensors.

These turns have been accompanied throughout by a transversal turn, the influence of technology, though this cannot be considered as a turn as such because it is not a paradigm or an epistemological way of understanding translation. Technology is a tool to help both translators and researchers, to help the market, and to better understand localization processes. Yet, technology is also necessarily changing the way scholars view audiovisual translation, and thus, the way research is carried out. Automatic translation, for instance, is moulding the way subtitling has been done 
so far. Translation in the cloud, too, is changing translators' habits and enables connection with other translators, software and practices. Social networks have also constituted a step forward in the way translators work and the extent to which they can now rapidly inquire about any doubt, to mention one advantage. Technological advances in the digitalization of images may perhaps bring about a solution for the traditional lip-sync and isochrony issues in dubbing (Chaume, 2019).

This article presents a due brief overview of these turns and identifies some of the major steps already undertaken in each turn, as well as possible research avenues that these turns are currently opening.

\section{The origins: Specific characteristics of AVT}

The first isolated contributions by Simon Laks (1957) and the special issue of Babel (1960) constitute the rather anecdotal conception of AVT as a field of study. However, the first work to be considered as proper research was Fodor's (1976) contribution to the field of dubbing, followed by some previously mentioned seminal articles in the seventies (e.g., Vöge, 1977) and eighties. All this research created the foundations for observing this professional and mostly hidden activity from a scientific standpoint (Chaume, forthcoming).

However, it was not until the nineties that all efforts centred on the process of audiovisual translation, which still required illustration and description, and so did the role of agents, markets, distributors, dubbing and subtitling companies, translators, dialogue writers, voice talents, dubbing directors, sound engineers, quality control specialists and so on. Research in that decade was flooded by such necessary contributions focusing on the peculiarities and specificities of audiovisual translation in comparison with conventional written modes of translation. In a way, this decade witnessed the inception of AVT theory. Nevertheless, the approach generally adopted in such studies could, in hindsight, be criticized as failing to comply with established research methodologies. Despite this, these first descriptions, mostly based on personal experience, have helped new researchers develop AVT theory. For instance, sociological and ideological studies in AVT are now based on researchers being able to access knowledge of the translation process of their objects of study. Before conceiving a valid methodological framework of research able to explain the various dubbing and subtitling norms, it was necessary to take the industrial process into account: what took place and how, when, where and by whom.

AVT scholars from all over the world are greatly indebted to a seminal article authored by Titford (1982), and further developed by Mayoral, Kelly \& Gallardo, who first published their article in Spanish in 1986, and later in English, in 1988. These authors expanded on Titford's concept of constrained translation and coined the term subordinate translation to refer to modalities such as the translation of comics, songs, advertising, and any type of AVT. Despite being applied primarily to subtitling, Mayoral et al. (1986) succeeded in extending this concept to all AVT types and made 
the first attempt to classify AVT according to the number of constraints each mode presented. The terms constrained translation and subordinate translation soon gained wide consensus in academic research and have been used and expanded by many other authors since. Nowadays, it is impossible, and hardly recommendable, to carry out any research in AVT without taking into account all the constraints taking place in the transfer process. Constraints are now understood as control variables in any descriptive or experimental piece of research in this field.

Parallel to the description of the transfer process, scholars expressed their interest in linguistic issues. Apart from preliminary research on the invasion of the English language in the subtitled and dubbed versions produced in other countries, most of which was carried out in a prescriptive and even apocalyptic fashion, there have been two other major linguistic issues that have attracted scholarly attention: the language of dubbing, or dubbese, and multilingualism in all AVT modes. Initially, research on calques was based solely on the comparison between ST and TT, but luckily the focus has shifted, and studies on dubbese and multilingualism now compare the TT to the ST, the TT to other TTs, and the TT to other domestic audiovisual products in a polysystemic fashion, and mainly by inquiring about the norms and habits that are responsible for the final linguistic outcome of the translation.

However, comparative studies went way beyond the study of microtextual samples, and, in line with the turns and interests of linguistics of the time, they soon began to focus on textual and discursive issues, by comparing and contrasting registers, dialects, pragmatic discourses and semiotic entities (for example: Hatim \& Mason, 1997; Mason, 1989).

In a way, this decade witnessed the inception of AVT theory.

\section{Descriptive Translation Studies}

The new century witnessed a step forward in AVT research. The industrial process and the description of the market and its agents had been largely dealt with in the nineties, mostly as far as dubbing and subtitling were concerned. The field needed to look ahead, because industrial processes did not change fast enough to justify further description. The influence of DTS, coming especially from translation theory and from literary translation soon paved its way into AVT investigation. Although DTS had been long established in this discipline, AVT needed time to first describe what it consisted of and how it was done (1990s), before entering the stage in which it could be studied in a rigorous and scientific manner (late 1990s and 2000s). Researchers soon realized that this field constituted fertile ground for the application of DTS methodology with the objective of mapping translation norms (or routines, trends, for other authors), strategies (techniques for others), and even translation methods, mainly foreignization and domestication. Academics started to compile coherent catalogues of dubbed and subtitled audiovisual texts in their own target languages, and they sought to describe - from an intentionally detached perspective - 
the macrotextual and microtextual operations that the original text underwent in order to match the target language and culture conventions. This research constituted an important step forward in AVT, and described what it was like in a certain space and time, thus contributing towards the general comprehension of this area.

The introduction of DTS in AVT research ran parallel to the integration of the Cultural Turn in this same field (see below). The cultural turn in AVT has mostly generated case-studies focused on one film or on TV series in which the fingerprints of ideology captured researchers' attention, and in which the ideological reasons behind translation solutions are the focal point of interest. However, DTS is not incompatible with cultural orientation. DTS is a methodology, whereas the cultural turn is a theory. That is why combined studies are also feasible, for example, using DTS methodology to draw ideological conclusions. Mentioning all the authors who have carried out research on ideology using DTS methodology would be an impossible feat. For this reason, two sample examples to illustrate this line of research should suffice: Gutiérrez Lanza's work on censorship under Franco's dictatorship in Spain (2011 and 2012, among many others), and Ranzato (2015) on culture-specific references.

Descriptive translation studies have helped researchers understand how AVT is shaped. Nevertheless, we still lack studies on large audiovisual and multimodal corpora, such as the ones based on the Pavia Corpus (Freddi \& Pavesi, 2009; Pavesi, 2014) and the Forli Corpus (Valentini, 2006). The language of dubbing, also known as dubbese (doppiaggese, synchronien, doblatgés, in other languages), is one of the most successful research fields which fall under the corpus umbrella.

Spanish scholars alone just to give an example, Díaz Cintas (2003 and 2004b, based on Lambert and van Gorp 1985), Chaume (2004, 2014), Gutiérrez Lanza (2005, 2008), Barambones (2012), and Martí Ferriol $(2010,2013)$ have proposed several frameworks of analysis that can result in helpful tools for new researchers starting any descriptive study. Such models of analysis take into account the concept of constraints or restrictions (so typical of audiovisual texts), as well as the specificities of an AVT commission, the way translated audiovisual texts are commercialized and presented to the public, the way translated audiovisual texts are received, and the different codes of meaning weaved into the audiovisual text and their implications in the translation process. These models also deal with the main notions of translation theory, such as strategies, norms, constraints and methods. Any translation issue (songs, film titles, humour, cultural references, intertextuality, language variation, multilingualism, etc.) can be studied using these frameworks. Quantitative and qualitative data are recommended for a descriptive study (i.e. microtextual contextualized samples over and above questionnaires and interviews inquiring about the translation process; in other words, the observation of behaviour in addition to the collection of verbal statements by the actors of the process). The compilation of a catalogue is also recommendable - though case studies can also be carried out without a catalogue - also, the outline of tentative norms (or translation trends or tendencies, Martínez Sierra, 2008) is the main goal of any descriptive study: seminal research, 
such as Goris (1993), who was the first scholar to formulate norms on a textual level in AVT, and Karamitroglou (2000), who did the same at a macrotextual level have been replicated and e tended during these last three decades.

In sum, DTS in AVT have a double and complementary general objective: searching for norms (Schäffner, 1998) or recurrent patterns in translation solutions, and, to go even beyond, the reasons behind those patterns. Generally speaking, in order to do this, researchers:

- decide which topic they are going to investigate, together with the audiovisual genre or genres they are going to tackle (usually the topic of research is also related or more specific to the genre selected).

- Compile a catalogue, or corpus, of audiovisual texts ensuring coherency in selection (for example, thrillers in a certain decade or significant period of time, e.g. Hollywood musicals in the post-classical era, Nordic Noir in the $21^{\text {st }}$ century, etc.).

- Filter the catalogue and obtain a smaller corpus, more manageable for their interests and analysis. Filters may vary according to the researcher's objectives. For example, generally, researchers do not stick solely to one dubbing company or one subtitler (unless they intentionally want to study the translational behaviour of a specific translator or dubbing company, for example). Filters also include selecting films according to certain temporal slots or periods (longer in diachronic studies, shorter in synchronic studies), according to different producers and distributors, according to a particular subgenre, etcetera.

- Interview the agents of the translation process by means of questionnaires, from which they retrieve qualitative data (collections of verbal statements by actors), that will be triangulated with the quantitative data derived from the microtextual analysis.

- Detect replacing and replaced segments in both target text and original text, usually by comparing them (microtextual analysis), though in this case it is advisable to start with the target text analysis and then proceed with the original text to search for the replaced segments, in a bottom-up fashion (observation of behaviour).

- Count recurrent strategies and calculate percentages of the strategies found in the target text. These percentages are usually displayed in tables or figures and are subsequently contrasted with the qualitative data retrieved in the questionnaires, in order to check the validity of both types of data. Data can be retrieved manually or otherwise with the use of specific software.

- Formulate norms according to the types of strategies found, for example, if levelling predominates in the analysis, the researcher can formulate the norm of standardization, or if taboo words have been generally avoided in the translation, the researcher can formulate the norm of euphemization, etcetera.

- Formulate the method of translation according to the norms (trends in smaller corpora, for instance, one single film) found in the analysis, that is, the researchers establish whether the norms found altogether follow a foreignizing trend or a domesticating trend. 
Corpora may vary substantially. If the researcher wants to really investigate norms, a vast digitalized electronic catalogue would be required in order to find recurrent patterns of behaviour in the translations. Only quantitative analysis of substantial catalogues may prove to be valid in formulating norms. Catalogues with textual samples compiled in databases or Excel files are the middle ground between electronic corpora and a case study (see below), and a good way out for the researcher who cannot use electronic corpora but still wants to find representative patterns of behaviour.

The approach adopted to deal with the data obtained can also vary: the researcher may want to look at the data from a pragmatic viewpoint (looking for contextual assumptions, presuppositions, implicatures, etc.), a semiotic and cinematographic viewpoint (dealing with the interaction of semiotic codes in the target and original texts and how these codes impinge on translation solutions), an ideological viewpoint (as mentioned above), and last but not least, a polysystemic approach, comparing the target translated audiovisual product to domestic audiovisual products belonging to the same genre in the target culture (Baños, 2014 ). In sum, DTS research looks for objectivity and representation, unless this methodology is applied to a case study, where a phenomenon is then studied in detail.

\section{Sociological studies}

The advent of digitalization has given rise to a new digital culture. Consumers' participation as cocreators in audiovisual production processes has been critically boosted in the past ten years. A new, more interactive and dynamic use of the web also invites formerly passive audiences to participate in the creation and translation of audiovisual content, in the development of new ideas and in the complex interplay of collective creativity. The fact that audiences now have become agents of production shifts the debate towards the concepts of empowerment and intervention. Passive consumers of AVT have become active consumers or prosumers, since this new democratic use of technology has allowed them to take on some of the power and responsibility that traditionally was solely in the hands of the producers.

Another critical area of research is that of activism (Pérez-González, 2016), that is, engagement, civic empowerment and dissent expressed in translated audiovisual content, mainly by means of amateur subtitling, and recently by means of gag dubbing, produced by ordinary citizens on digital media platforms on the web. This development brings on the Social Turn in AVT.

New values and norms start with the selection of materials to be translated. In the past, distributors decided what to broadcast, what to sell and what not to sell or distribute to TV stations. Now, fansubbers and fandubbers decide what to subtitle and what to dub, just by accessing the web and finding newly released products, or products that are deemed worthy or that perhaps have some 
kind of status in their community. Therefore, the habitus can be changed, as indeed happens. Audiences are weary of consuming audiovisual products in a traditional, linear and scheduled way. Orrego-Carmona (2015) studies non-professional subtitling use in Spain as a successful way to overcome linguistic barriers, and gives an overall picture of users' engagement with audiovisual content describing their attitude towards official subtitling as against non-professional subtitling. Digitalization and empowerment merge in a new type of subtitling, the so-called creative subtitling (both inter and intralingual), which attributes new functions to subtitles over and above the simply communicative one, which characterizes interlingual subtitling. Subtitles as footnotes, captions placed anywhere on the screen, subtitles as creative titles, emerging from coffee machines or chimneys, captions placed next to the onscreen characters' mouths (as is the case in NCIS, Bellisario \& McGill, 2003-), are new forms of creative subtitles, which aesthetically communicate meaning beyond that of their semantic value - as was the case with Monty Python and the Holy Grail's (Forstater, White, Gilliam, \& Jones, 1975) metalinguistic funsubs back in the seventies, an invented pidgin which included words containing Swedish and Dano-Norwegian characters.

The increasing use of free-commentaries has flooded the web, both in the form of funsubs and fundubs (not to be confused with fansubs and fandubs), that is, humoristic subtitles and dubbings made for fun, thus intentionally unfaithful to the original text. Free-commentaries in the realm of dubbing can encompass gag dubbings, fake dubbings and also newer experiments, such as the so-called literal dub versions. A literal dub version is a literal music video that replaces the original lyrics of a song with newly invented lyrics that ironically describe the visuals in the video - as is the case in the popular literal music clips You're beautiful, by James Blunt (Blunt, Skarbek \& Ghost, 2004), Total Eclipse of the Heart, by Bonnie Tyler (Steinman, 1983) - among many others. Funsubbers intentionally replace the lyrics with new ones that literally represent what is being seen on screen; this results in very entertained viewers who can't help laughing at the final outcome, especially when they are familiar with the original text. These literal video versions are subtitled and dubbed, resulting in a new, and apparently weird, product consumed by target audiences all over the world. The opening song of My Little Pony: Friendship is Magic (Faust, 2010-2015) has been dubbed into Spanish, then funsubbed and subsequently also fundubbed into this same language. The funsubbed and fundubbed versions are literal video versions of this clip, displaying a nonconformist irreverent tone intentionally inappropriate for a child audience.

As far as subtitles are concerned, it is worth mentioning the so-called mondegreens and soramimis. A mondegreen is a misunderstood word or phrase resulting from a mishearing of something sung or said, while soramimi is a Japanese term that refers to the same phenomenon, but that occurs when a word from a foreign language is homophonically translated into one's own language (the Italian canzoni travisate, for example). This is the case of the Bollywood song Dilbar, by Sushmita Sen (Anjaan, Saifi, \& Rathod, 1999), which now globally goes by the name of The Nipple Song (almost 15 million views on YouTube), precisely because the chorus line in Hindi resembles the English word nipple. In the gag subtitling or funsub found on the web, the fake translation of this song tries to integrate the word nipple coherently, and the lyrics have been funsubbed accordingly, with plenty of 
naïve sexual references in line with the main mishearing. This intended misinterpretation is the result of a near-homophony, such as the one that gave rise to this term: it seems that American writer, Sylvia Wright, coined the term when, as a young girl, she misheard the lyrics of a Scottish ballad: "...And laid him on the green..." was mistaken for "... and Lady Mondegreen..." (Konnikova, 2014).

Apart from the humoristic use of subtitles, an activist use, too, emerges through fake subtitles or honest subtitles. Fake subtitles often conceal a political agenda, by distorting real news coverage and engaging with specific ideological spaces developed by recent crises. They usually encompass parodies, such as the well-known Hitler-related Downfall (Eichinger \& Hirschbiegel, 2004) parodies. Such parodies are widely popular on the web and in many countries, though they can be subjected to censorship. For example, Muslim communities complain that several videos on the platform BoreMe are constantly distorted with false subtitles in order to promote an anti-Islam bias based on hostile and false propaganda, thus contributing towards ignorance and conflict.

In the following example, Nigel Farage gesticulates in the European Parliament in a speech that was gushed over by the right-wing press. The subtitles, however, make fun of him and his political agenda (Example 1).

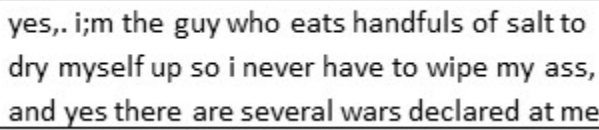

Example 1. Nigel Farage - fake subtitles (original spelling and layout) (Koshy, 2017).

On the other hand, honest subtitles are subtitles that denounce the usually hidden agenda of politicians, by expressing the underlying contents in an explicit manner, rather than reproducing what they actually say. Therefore, instead of a verbatim reproduction of a politician's speech, the new clip with honest subtitles depicts what politicians really think, instead of what they say. For example, in the well-known footage in which Theresa May succeeds David Cameron as Prime Minister of the United Kingdom the honest subtitles, which supposedly represent what she really thinks are quite different from the original speech (Examples 2, 3 and 4). Honest subtitles therefore bring to the surface all that some politicians and prominent people cannot openly say, but allegedly think to themselves.

\begin{tabular}{|l|l|}
\hline \multicolumn{1}{|c|}{ Real speech } & \multicolumn{1}{c|}{ Honest subtitles } \\
\hline $\begin{array}{l}\text { I have just been to Buckingham Palace, where } \\
\text { her Majesty, The Queen, has asked me to form } \\
\text { a new government and I accept it }\end{array}$ & $\begin{array}{l}\text { I have just been to Buckingham Palace, } \\
\text { whe her Majesty, The Queen, } \\
\text { has asked me to get a grip on this shitstorm } \\
\text { and I can't believe my luck. }\end{array}$ \\
\hline
\end{tabular}

Example 2. Teresa May - honest subtitles (Harvey, 2016). 


\begin{tabular}{|c|c|}
\hline \multicolumn{1}{|c|}{ Real speech } & Honest subtitles \\
\hline David's legacy is about social justice. & David's legacy is about his career suicide. \\
\hline
\end{tabular}

Example 3. Teresa May - honest subtitles (Harvey, 2016).

\begin{tabular}{|l|l|}
\hline \multicolumn{1}{|c|}{ Real speech } & \multicolumn{1}{c|}{ Honest subtitles } \\
\hline Together we will build a better Britain. & Together we will build a bitter Britain. \\
\hline
\end{tabular}

Example 4 Teresa May - honest subtitles (Harvey, 2016).

Creative subtitles have their roots in fansubs (Díaz-Cintas and Muñoz, 2006; Ferrer Simó, 2005; Orrego-Carmona, 2015), a still increasingly fashionable phenomenon. All this peripheral, but also highly interesting, new usage of creative subtitles in fansubbings, fake subtitles, honest subtitles, gag subtitling, etcetera, is inducing the industry to adopt new creative and active behaviours by incorporating them into their new modern products. They can also be helpful with subtitling conventional issues, such as the translation of multilingual movies including languages other than the main language of the film. These other languages can be subtitled using creative subtitles, for example.

The same goes for the concept of accessible filmmaking (Romero-Fresco, 2012), where creative subtitles can be part of the production process, thus avoiding the need of inserting postproduction subtitles. The majority of access services that technological developments have spawned, including access services to overcome sensorial and linguistic barriers, have always been added later, during the film or audiovisual post-production process. Only once the production is finished and the final cut is edited, and only at a late stage, can the product be dubbed, subtitled, subtitled for the deaf and hard-of-hearing, respoken, audio described, voiced-over, surtitled, etcetera. Romero-Fresco (2012) was the one to coin the concept of accessible filmmaking, referring to a way of making audiovisual products that incorporates linguistic and sensorial access as an integral part of the production, by means of close collaboration between translators and film directors. Creative subtitles can be part of the filmmaking process, by including experts in translation, localization and accessibility in the production team, thus, with foresight, avoiding typical localization hurdles, such as the positioning of subtitles against coloured backgrounds or certain translation issues, reading speed issues, lip synchrony in close-ups, and so on. Creative subtitles, therefore, have the potential to foresee and sort out all these typical problems by integrating AVT during the filmmaking process. The same goes for accessibility in museums.

Finally, voluntary subtitling has received recognition from both professionals and viewers, especially when they are produced with the intent of reaching people in countries or regions afflicted by war, or otherwise, using them to divulge scientific findings, once again with the intent of empowering people who otherwise would have fewer resources to enjoy a better life. They are commissioned by some non-profit associations, also known as crowd sourcing (Díaz-Cintas, 2013), such as TED, Universal Subtitles and Khan Academy. 
In sum, sociological studies in AVT usually have the main objective of analysing the figure and role of the translator, their work conditions, their habitus, the so-called symbolic capital - the value of which may be restricted or aggrandized by the historical context in which it is accumulated the field or setting in which agents and their social positions are located, the market and its fluxes, the transmission of existing cultural values and norms from one generation to another, the empowerment of audiences, the empowerment of translators, the emergence of new consumption habits, and so on and so forth. The creation of new consumption habits in AVT can be exemplified by the rate with which new audiences are getting used to voiced-over reality shows, to mention one example. Audiences are also revealing a different tolerance threshold in terms of, for example, the accuracy of lip synchrony in dubbing or reasonable reading speed in subtitling, to mention a few examples. This general objective is usually attained when researchers do the following:

- design questionnaires, that is, tools for collecting data based on having a given subject respond to a set of oral or written questions, and/or conduct surveys, which are larger processes of gathering data that may involve a wide variety of data collection methods, including questionnaires. Nowadays, online questionnaires and surveys enable information to be gathered from a large audience. The more data the researcher gathers, the clearer the picture becomes. All this information gives stakeholders the ability to create new strategies and follow audience trends. Analysing data gathered via these tools can be used to generate predictions and even replace traditional habits with more modern ones.

- Conduct personal interviews and focus groups. A focus group is a small-group discussion usually 10 or fewer individuals - guided by the researcher. The group may consist of volunteers gathered to discuss a particular product or idea. This method is used to discover opinions, ideas and reactions on a designated topic, and to guide future action. These groups are presented with a series of questions or statements on which they can freely share their opinions. They may also be asked to try a new product, such as a new kind of subtitling or dubbing or audio description method, for example, or they may simply be invited to react to a specific dubbed, subtitled or audio described audiovisual clip they have just viewed. All these responses are studied in order to measure the reaction of the larger market population.

- Use both qualitative and quantitative data. Qualitative research in AVT is used to obtain a deeper understanding of the underlying reasons, opinions, and motivations of all the agents involved in the process of translation, be it distributors, translators, or even the audience. It provides insights into any given issue discussed, and entices the development of ideas or hypotheses for potential quantitative research. Qualitative research is also used to reveal norms in shared values and opinions, and is usually triangulated with quantitative data; in other words, the qualitative data obtained from interviews, surveys and focus groups is compared with the empirical data obtained in the microtextual analysis of the corpus chosen. Qualitative data collection methods vary using unstructured or semi-structured 
techniques. Sample size is typically small, and respondents are selected to satisfy a given quota of the different roles in the AVT process (producers, distributors, TV stations, localization companies, translators, dialogue writers, dubbing directors, dubbing actors, quality assurance managers, engineers, different audiences, etc.). Quantitative research is typically employed to quantify recurrent patterns of behaviour in the translations by generating numerical data or data that can be processed into usable statistics. Statistics is not mandatory in AVT research, sometimes only percentages are needed to show a particular translation pattern. It is used both to quantify attitudes, opinions, behaviours, and replacing and replaced segments in the translation and in the original texts, with the aim of generalizing results from a larger sample population. Quantitative research uses measurable data to formulate norms and uncover translation patterns at a macro and micro level.

- Use critical discourse analysis (CDA) as a theoretical background to unveil how societal power relations are established and reinforced through language use. Although CDA is sometimes mistaken for a research methodology, it is a powerful theoretical framework that produces insights into the way discourse reproduces (or resists) social and political inequality, power abuse or domination. Thus, translation can also be studied under the lens of CDA, because it is through translation that a vast amount of information is made available, or censored. Translation can either legitimize or battle current political interpretations of violent conflicts, gender inequalities, power relations, and so on.

- Investigate agency and structures. Structures are the factors of influence, such as social class, religion, gender, ethnicity, age, customs, etcetera - that determine or restrict the agents and their decisions: what to translate, how to translate, what to revise, how to revise, how the information is presented in the translation or described in an $A D$, for example, which audiovisual products are selected for translation, to which textual and extratextual strategies has the translator resorted, how the different voices in the clip and the translation are identified, which voices are heard and which ones are silenced, and so on and so forth. Agency, on the other hand, is the ability of translators, and currently, of the audience, to act independently and make their own free choices.

- Consequently, outline strategies that represent resistance and activism, moving from the concept of translation as a mere linguistic transposition, to translation as a force and tool "of power, resistance, rebellion, and even revolution" (Tymoczko, 2010). This approach is particularly welcome in research that investigates gender issues, religious issues, censorship and sex.

- Base their findings on the theoretical background of Bourdieu, later on applied to translation by Cronin (2006), Bielsa (2010), Villanueva, Hermoza \& Bravo (2017) and etcetera.

- This social turn in audiovisual translation can be summarised as follows: new audiences aware of the world surrounding them, consequently take action as consumers, prosumers and translators. The producers and distributors of audiovisual contents will have to take into account the social, co-participating and unrestricted nature of this new scenario whereby contents have to be produced together with the audience and no longer for the audience. 


\section{Cognitive studies}

The 2010s has witnessed the unstoppable introduction of process research in AVT, which is now here to stay (Kruger, Szarkowska \& Krejtz, 2015; Orrego-Carmona, 2015, just to mention a few). Although some interesting preliminary studies on reception were first conducted in the 2000s, the introduction of technology has dramatically changed the way research is being done in AVT, and has emulated the way in which research has been done in other translation (and linguistic and psychological) domains, where tools such as eye-trackers had already constituted a successful tool in exploring the human brain. Eye-tracking systems have been used to identify current reading speeds in subtitling - both interlingual and intralingual - to compare different types of subtitles both for sighted, deaf, and partially sighted audiences - to analyse minor details in films, to study the reception of amateur subtitles, to analyse viewers' response to the new promising field of accessible filmmaking, to discover whether the audience is, indeed, constantly watching the onscreen characters' lips in dubbing, to discover where sighted audiences look (with the intent of using that information to create audio description, instead of laying that responsibility in the hands of the subjective audio describer), to learn and teach audiovisual translation taking into account cognitive data, and so on and so forth. Eye-trackers are often combined with biometric sensors, used to identify the translators' and audience's physical and behavioural traits, such as vein patterns, voice patterns, iris patterns, heart rate, sweat on the skin, and face detection or recognition. Biometric sensors are transducers that change a biometric treat of a person into an electrical signal; this can then be processed and analysed. In the case of AVT, only heart rate (Rojo, Ramos \& Valenzuela, 2014) and electroencephalograms (Kruger, Soto-Sanfiel, Doherty \& Ibrahim, 2016) have attracted the interest of researchers but we still lack studies about face recognition, iris patterns, and galvanic skin response. Experimental studies using physical measures are still scarce, due to the difficulty in finding and selecting subjects, the complexity of analysing the data retrieved from sensors, and most of all, the cost of such sensors, and the highly specialized knowledge required to use them.

Experimental designs start by raising a research question that needs to be as simple and tangible as possible, clearly stating the variables at play. Once the research question is established (e.g., "Do spectators set their gaze on the lips of onscreen actors in dubbed films?"), objectives are set, variables are identified (dependent, independent and intervening variables), hypotheses - if need be - are formulated, and participants are selected according to the number of subjects needed, age, gender, background, and so on. Sometimes, an additional control group is needed, other times one group suffices for the experiment (in so-called pre-experimental research). Informed consent and nihil obstat declarations from the ethics offices of the academic institutions concerned are also needed to proceed with such experiments. The task and necessary materials, too, need to be prepared for the experiment. Subjects have to carry out a particular task for researchers to check their response to something. The researchers also have to decide what audiovisual genre or genres they are going to use, how many audiovisual products - and their duration - will be watched by their subjects, how to edit the clips (if need be), which task the subjects 
will carry out (for example, filling in a questionnaire when the clip is over), which information is needed from the participants, which tests are needed to measure all variables at play, how to pilot the experiment, etcetera.

Therefore, the main objective of cognitive studies is to analyse what happens in the translator's or audience's brains, to get inside their black box in order to unveil the reasons behind decisions, feelings, and way of facing and tackling a translation or consuming a certain translated audiovisual text, bringing feelings and body response to the surface. In translation studies, Think Aloud Protocols (TAPs) were used in the nineties, to gain insight into what translators were thinking while translating particular segments from selected texts. Choice Network Analysis (CNA) has been used more recently to compare the translations of the same source text carried by several translators in order to empirically obtain possible options, that is, a set of potential solutions available when translating each translation issue.

Studies on reception were the precursors of this interest in the human brain faced with a translation task. The first reception studies, carried out in Italy, Poland and Spain, and now carried out worldwide (for example, more recently in Japan, see O'Hagan and Sasamoto, 2016; or in Iran, see Ameri, 2018), inquired about the response of a selected audience before a dubbed or subtitled film - and more recently before a film that has been audio described or subtitled for the deaf - and sometimes by comparing this to the response obtained from native speakers watching the same films or clips without translation. Action-research has also been a precursor of experimental research in AVT (see Neves, 2005), where a method is designed, put into practice in an experiment, and the same experiment used to better the design of the method, rearranged as many times as required.

In sum, cognitive studies:

- analyse cognitive processes, both in the translator's brain and, especially nowadays, in the audience's brains, and indulge in translation process research.

- Deal with both quantitative and qualitative data.

- Obtain the data from new technological devices (namely, in AVT, the eye-tracker, and secondarily, other biometric sensors) and/or from questionnaires and surveys. They also use specific software, such as TRANSLOG - developed to study and acquire objective, digital data of human translation writing processes - or E-Prime to study behavioural research, by providing millisecond precision timing to ensure the accuracy in the data retrieved;

- Can assess and evaluate translation competence.

- Can assess and evaluate the audience's likes and dislikes.

- Can study in detail minor aspects of translation issues (lip-syncing in close-ups in dubbing, reading speed in interlingual or intralingual subtitling, the use and impact of emoticons in $\mathrm{SDH}$, recognition of icons in audio description, playability and game experience 
in videogame localization, incorporation of accessibility indicators in the film production process, to name just a few).

- Use experiments as a simulation of real settings.

- Validate or refute hypotheses.

- Help stakeholders to know more about their audiences.

\section{Case studies with a cultural approach}

Although Saldanha and O'Brien (2013) consider case studies as a distinct methodological paradigm, they are not opposed to cognitive studies, sociological studies or descriptive studies. Case studies are opposed to corpus studies. In between electronic corpora and case studies, we can find studies researching a manageable catalogue of audiovisual texts, that is, a set of texts sharing some characteristics which can, at any given time, be filtered so as to obtain a small corpus that can be manually analysed by a single researcher:

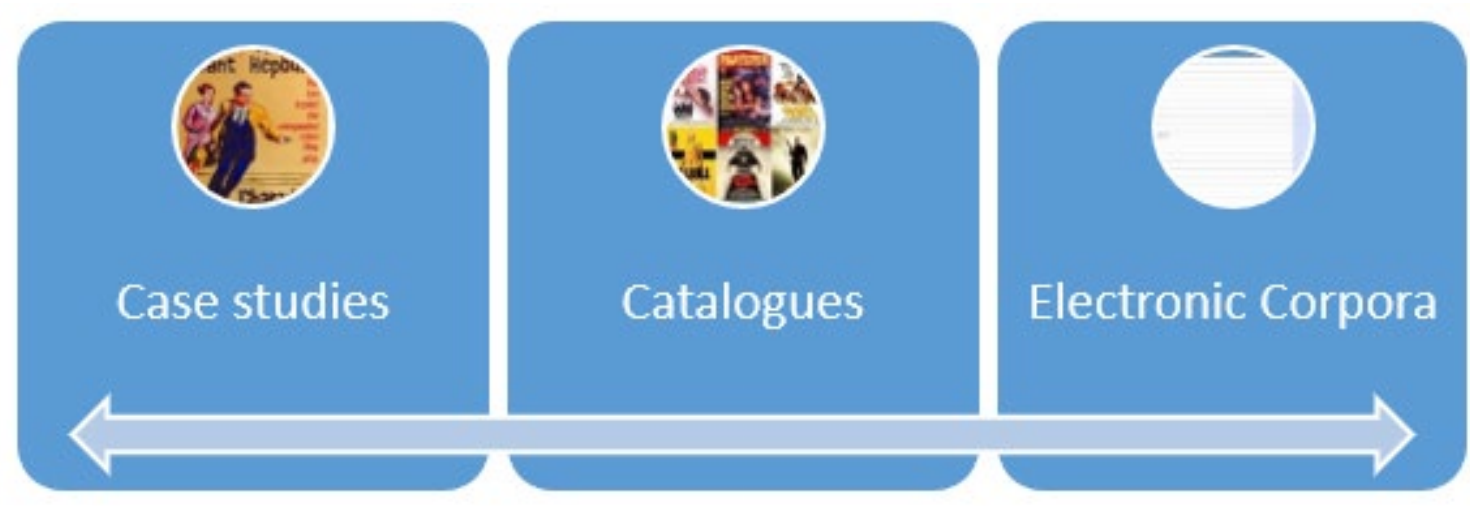

Figure 1. Different possibilities for the researcher to build a corpus.

Case studies are not a paradigm, nor any specific turn. They are a feasible way forward in research in a university context, where promotion depends on writing a PhD thesis, book, or research project on a topic dealing with scientific methodology. In general, case studies:

- analyse a phenomenon in meticulous detail;

- allow flexibility;

- enable quantification - usually combining quantitative data with qualitative data;

- follow an inductive method;

- can be developed further by following any theoretical background: sociological approaches, cognitive approaches, cultural approaches, hermeneutic approaches, and so on.

Case studies seem to be ideal in cultural studies. The latter tend to be particular studies focused on the big issues of the Cultural Turn: the concepts of ideology, otherness, post-colonialism, power, resistance, patronage, censorship, genetic analysis (Richart Marset, 2012, 2015; Zanotti, 2018, 
bringing to light the documented archive generated in each stage and the ideological moves behind each version), intentional use of multilingualism, identity, gender, and more recently gender stereotypes, among others, now receive scholarly attention, after being widely ignored throughout the research phase in the translation process (1990s) and in descriptive studies, which focused mainly on the translation product (2000s). Researchers preferred to establish an uncompromised debate on translation norms, but rarely went beyond the reason for those norms, and scarcely questioned the actual reasons behind norms and translation techniques. Sanitized descriptive approaches are now substituted by burning discussions and fiery appeals for or against certain translation solutions that are no longer considered to be innocent strategies, but rather as intentional and deliberate choices, many times indicating a hidden agenda stashed throughout the text intended to indoctrinate audiences, to perpetuate - or inoculate - some values, and to shape their will.

In sum, case studies aim to:

- analyse a particular translation, translator or author;

- are usually based on the Cultural Turn, but can also be based on other paradigms;

- try to clarify the ideology behind the translation solutions found in the text;

- deal with concepts and aspects such as ideology, patronage, gender and the ones mentioned above;

- usually compare the source text to the target text (comparatist studies);

- intend to find the strategies used to overcome the conventional translation issues: humour, multilingualism, language registers, film titles, songs, etc.;

- find translation techniques or strategies, which, when conveniently grouped, can explain translation norms, and subsequently, the translation method used throughout the text (if any);

- take into account audiovisual translation constraints, most of the times;

- can deal with microtextual translation issues, but also with preliminary and matricial norms (issues of format, conventions and typographical usages, paratextual elements, etc.).

\section{Conclusions}

In the present century, AVT research has moved further ahead. The nineties were devoted to explaining the AVT process, its distinctive characteristics (mainly, constraints), and the role of the agents involved in the process. The new century witnessed the first turn in AVT research, the Descriptive Turn, and the first decade of the century was necessarily flooded with descriptive studies (DTS), revealing which translation norms regulate the behaviour of AVT in different countries and periods. Such systematic and scientific methodology certainly enabled AVT to evolve. Once the discipline was mature, the 2010s welcomed the Cultural Turn, and more recently, the Social Turn, and this has dramatically changed the perspective of audiovisual translation. Cultural studies delve into ideological issues while sociological studies examine the traditional roles of distributors, exhibitors, dubbing and subtitling companies, translators, dialogue writers 
and more important, the enhanced role of various audiences, who are now more active and interconnected than ever before; they now decide what to consume, when to consume it, how to consume it and where to consume it.

The role of technology has played an essential part in the evolution of AVT, both in professional and academic settings. Artificial intelligence, machine translation, translating in the cloud, collaborative dubbing carried out in different countries and companies and then edited in one single company, dubbing and subtitling apps, and so on, have all changed the way to practise AVT, to distribute it, and to consume it. Technology can also change dubbing and subtitling norms, subtitling for the deaf and hard-of-hearing and audio description norms, videogame localization norms, since it now allows moulding the images to fit the translation into the onscreen characters' mouths (Chaume, 2018), dubbing the same film in multiple studios based in different countries, widening subtitles, including captions and props in other screen positions, including emoticons in subtitles, drawing creative subtitles, making many AVT modes in the same product available, etcetera.

Technology is also responsible for the flourishing of research tools in academic settings, such as eyetrackers, biometric sensors and specific software to record the translators' and spectators' reactions, as well as to practise AVT in the cloud, using dedicated software to subtitle, to audio describe, to dub, etc. This has given rise to a Cognitive Turn that is currently gaining ground in this field.

The use of new apps easily enables domestic subtitling and dubbing. In dubbing alone, for example, new apps enable users to choose an audio recording from movies, shows, music or the web, and record a video of themselves dubbing over that recording, thus empowering themselves and creating a new clip that can also be uploaded to the Internet, and subsequently viewed (and translated) by thousands of other spectators. Other apps are used to subtitle and to describe. They are also used to create fundubbings, funsubs and funads, thus breaking the AVT routines and norms (inducing confusion among stakeholders, now plunged into a sense of bewilderment), creating a collective identity and, in sum, creating what is called a reverse agenda-setting and agendamelding (Ragas and Roberts, 2009).

AVT has experienced a vast process of redefinition, which has run parallel to the four turns mentioned and to the irruption of technology. AVT has rapidly extended its borders to include other localization processes, such as Video Game Localization, transcreation, transmedia projects, the adaptation of television franchises and transnational remakes, among other new interesting and emerging forms of localization, such as non-professional subtitling and dubbing. All these new market processes are shaping a different audiovisual translation model, when compared to the one we were accustomed to at the turn of the century. Research on TV formats and how an adapted franchise differs from its original counterpart, research on transcreations, where several semiotic layers of the original product also can be localized and manipulated, research on transnational remakes, 
which reveal a multimodal process of translation, research on accessibility in museums, etcetera, have changed the way we have been understanding AVT so far.

AVT has not yet reached its horizon. Historical studies, theoretical concepts and notions applied to AVT, philosophical studies, hermeneutic studies, postcolonial studies, narrative theory, among others, have not yet found their own niche in AVT. A comprehensive history of AVT, for instance, is still needed, just to mention one example. Apart from the urgent need for such research, attention needs to be paid on the field of redubbing and resubtitling (Chaume, 2007) and the reasons behind their production. AVT didactics is another promising field, especially considering the possibilities introduced by new online technologies. Other so-called turns, like the abusive turn (Nornes, 1999) and the demotic turn (Pérez-González, 2014), have not been mentioned in this article because they easily fit into broader paradigms such as the cultural and the sociological turn, respectively.

Audiovisual Translation does not yet demand a new theory of translation, though it is definitely pushing some translatological theoretical concepts against the ropes.

\section{Biographical note}

Frederic Chaume, PhD is a Professor of audiovisual translation at Universitat Jaume I (Spain), where he teaches audiovisual translation theory and dubbing; and Honorary Professor at University College London (UK), Universidad Ricardo Palma (Perú) and Universidad Peruana de Ciencias Aplicadas (Perú). He is author of the books Doblatge i subtitulació per a la TV (Eumo, 2003), Cine y Traducción (Cátedra, 2004), Audiovisual Translation: Dubbing (Routledge, 2013), and coauthor of Teories Contemporànies de la Traducció (Bromera, 2010) and La Traducción para el Doblaje: Mapa de Convenciones (UJ, 2016). He has also coedited two books (La Traducción en los Medios Audiovisuales; La Traducción Audiovisual: Investigación, Enseñanza y Profesión) and special journal issues (Perspectives, Prosopopeya) and is the director of the TRAMA book series (Publicacions de la Universitat Jaume I), the first collection of monographs on audiovisual translation. He has given several keynote lectures on audiovisual translation and translation for dubbing in international translation studies conferences and many European and American universities, and also teaches regularly in some of them (University College London, Universidad Ricardo Palma, Universidad de Granada, Università di Torino, etc.). He coordinates the research group TRAMA (www.trama.uji.es) and has been awarded the Berlanga Award and the ATRAE Xènia Martínez Award for his support to audiovisual translation and his constant university training in this field.

\section{References}

Ajaan, S. (1999). Dilbar, Dilbar [Recorded by Sushmita Sen]. On Sirf Tum [CD]. New Delhi, India: TSeries Music. 
Ameri, S., Khoshsaligheh, M., \& Farid, A.K. (2018). The reception of Persian dubbing: a survey on preferences and perception of quality standards in Iran. Perspectives, Studies in Translation Theory and Practice, 26(3), 435-451.

Babel, 6(3). (1960).

Baños, R. (2014). Orality Markers in Spanish Native and Dubbed Sitcoms: Pretended Spontaneity and Prefabricated Orality. Meta 59(2), 406-435.

Barambones, J. (2012). Lenguas minoritarias y traducción: la traducción audiovisual en euskera [Minority languages and translation: audiovisual translation in Basque]. Castelló de la Plana: Servei de Publicacions de la Universitat Jaume I. Col·lecció TRAMA.

Bellisario, D.P., \& McGill, D. (Creators) (2003-present). NCIS [Television series]. U.S.:Belisarius Productions, Paramount Network Television, CBS Paramount Network Television (Producers).

Bielsa, E. (2010). The sociology of translation: Outline of an emerging field. MonTI: Monografías de traducción e interpretación, 2, 153-172.

Blunt, J., Skarbek, S., \& Ghost, A. (2004). You're Beautiful [Recorded by James Blunt]. On Back to Bedlam [CD]. London, England: Atlantic - RCA.

Brant, R. (1984). The History and Practice of French Subtitling (Unpublished MA Thesis). University of Texas, Austin.

Carbonell, O. (2018). Proyecto docente e investigador [Teaching and research project] (Unpublished Professorship Treatise). Universidad de Salamanca, Salamanca.

Chaume, F. (2004). Cine y traducción [Cinema and translation]. Madrid: Cátedra.

Chaume, F. (2007). La retraducción de textos audiovisuales: Razones y repercusiones traductológicas [The retranslation of audiovisual texts: Reasons and translation repercussions]. In F. Ruiz Noguera \& J. J. Zaro Vera (Eds.), Retraducir: Una nueva mirada (pp. 49-67). Málaga: Miguel Gómez Ediciones.

Chaume, F. (2014). Audiovisual translation: dubbing. London \& New York: Routledge.

Chaume, F. (2019). Audiovisual translation in the age of digital transformation: industrial and social implications. In I. Ranzato \& S. Zanotti (Eds.), Reassessing dubbing: historical approaches and current trends (pp.1-40). Amsterdam and Philadelphia: John Benjamins.

Chaume, F. (forthcoming). Audiovisual Translation. In Á. Vidal Claramonte \& R. Valdeón (Eds.), The Routledge handbook of Spanish translation studies. London \& New York: Routledge.

Cronin, M. (2006). Translation and Identity. London \& New York: Routledge.

De Higes Andino, I. (2014). The translation of multilingual films: modes, strategies, constraints and manipulation in the spanish translations of 'It's a free world'... Linguistica Antverpiensia, New Series, 13, 211-231.

Delabastita, D. (1989). Translation and mass-communication: Film and TV translation as evidence of cultural dynamics. Babel 35(4), 193-218.

Díaz Cintas. J. (2003). Teoría y práctica de la subtitulación. Inglés-español [Theory and practice of subtitling. English-Spanish]. Barcelona: Ariel Cine.

Díaz Cintas, J. (2004a). In Search of a theoretical framework for the study of audiovisual translation. In P. Orero (Ed.), Topics in audiovisual translation (pp. 21-34). Amsterdam \& Philadelphia: John Benjamins. 
Díaz Cintas, J. (2004b). Introduction. Audiovisual translation: An overview of its potential. In J. Díaz Cintas (Ed.), New trends in audiovisual translation (pp. 1-18). Bristol, New York \& Ontario: Multilingual Matters.

Díaz Cintas, J. (2009). New trends in audiovisual translation: language transfer on screen. Bristol: Multilingual Matters.

Díaz Cintas, J. (2013). The technology turn in subtitling. In M. Thelen \& B. Lewandowska-Tomaszczyk (Eds.), Translation and Meaning. Part 9. Maastricht: Zuyd University of Applied Sciences.

Díaz-Cintas, J., \& Muñoz, P. (2006). Fansubs: audiovisual translation in an amateur environment. The Journal of Specialised Translation, 6, 37-52.

Eichinger, B. (Producer), \& Hirschbiegel, O. (Director). (2004). Downfall [Motion picture]. Germany, Italy \& Austria: Constantin Film.

Faust, L. (Creator) (2010-2015). My Little Pony: Friendship is magic [Television Series]. Canada \& U.S.: Lauren Faust \& Hasbro Studios.

Ferrer Simó, M. (2005). Fansubs y scanlations: la influencia del aficionado en los criterios profesionales [Fansubs and scanlations: the influence of the amateur on professional criteria]. Puentes 6, 27-44.

Fodor, I. (1976). Film dubbing: phonetic, semiotic, esthetic and psychological aspects. Hamburg: Helmut Buske.

Forstater, M., White, M. (Producers) \& Gilliam, T., Jones, T. (Directors). (1975). Monty Python and the Holy Grail [Motion picture]. United Kingdom: EMI Films.

Freddi, M., \& Pavesi, M. (2009). Analysing audiovisual dialogue. Linguistic and translational insights. Bologna: Clueb.

Gautier, G.L. (1981). La traduction au cinéma: nécessité et trahison [Film translation: necessity and betrayal]. La revue du cinema, 363, 101-118.

Goris, O. (1993). The question of French dubbing: Towards a frame for systematic investigation. Target 5(2), 169-190.

Gutiérrez Lanza, C. (2005). EDT basados en corpus textuales informatizados: perfeccionamiento metodológico en TRACEci [EDT based on computerized text corpus: methodological improvement in TRACEci]. In P. Zabalbeascoa Terrán, L. Santamaría Guinot \& F. Chaume (Eds.), La traducción audiovisual. Investigación, enseñanza y profesión, (pp. 87-98). Granada: Comares.

Gutiérrez Lanza, C. (2008). Traducción inglés-español y censura de textos cinematográficos: definición, construcción y análisis del Corpus 0/Catálogo TRACEci (1951-1981) [EnglishSpanish translation and censorship of cinematographic texts: definition, construction and analysis of Corpus 0/Catalog TRACEci (1951-1981)]. In R. Merino (Ed.), Traducción y censura en España (1939-1985). Estudios sobre corpus de cine, narrativa y teatro, (pp. 97-240). León: Universidad de León; Vitoria: Universidad del País Vasco.

Gutiérrez Lanza, C. (2011). Censors and censorship boards in Franco's Spain (1950's-1960s): An overview based on the TRACE cinema catalogue. In D. Asimakoulas \& M. Rogers (Eds.), Translation and Opposition (305-320). Clevedon: Multilingual Matters. 
Gutiérrez Lanza, C. (2012). Censorship and TV dubbing in Spain: From movie of the week to estrenos TV. In R. Rabadán, T. Guzmán \& M. Fernández (Eds.), Lengua, traducción, recepción: en honor de Julio César Santoyo - Language, translation: to honor Julio César Santoyo, 2 (pp. 223225). León: Universidad de León.

Harvey, J. (2016, July 20). Retrieved from https://www.youtube.com/watch?v=-8P1K11QyQo

Hatim, B. and Mason, I. (1997). The translator as communicator. London: Routledge.

Hendrickx, P. (1984). Partial dubbing. Meta 29(2), 217-218.

Herbst, T. (1987). A pragmatic approach to dubbing. EBU Review. Programmes, Administration, Law, $28(6), 21-23$.

Hochel, B. (1986). Communicative aspects of translation for TV. Nouvelles de la FIT, 5(3), 151-157.

Karamitroglou, F. (2000). Towards a methodology for the investigation of norms in audiovisual translation. Amsterdam: Rodopi.

Konnikova, M. (2014, December 10). Excuse me while I kiss this guy. The New Yorker. Retrieved from https://www.newyorker.com/science/maria-konnikova/science-misheard-lyricsmondegreens

Koshy, Y. (2017, May 10). The new wave of satire for our morbid political landscape. Retrieved from https://www.vice.com/en uk/article/53n9v8/the-new-wave-of-satire-for-our-morbidpolitical-landscape

Kruger, J.-L., Szarkowska A., \& Krejtz I. (2015). Subtitles on the moving image: an overview of eye tracking studies. Refractory, 25. Retrieved from https://refractory-journal.com/volume-252015/

Kruger, J.-L., Soto-Sanfiel., M. T., Doherty, S., \& Ibrahim, R. (2016). Towards a cognitive audiovisual translatology: Subtitles and embodied cognition. In. R. Muñoz (Ed.), Reembedding translation process research (pp. 171-194). London: John Benjamins.

Laks, S. (1957). Le sous-titrage des films. Sa technique. Son esthétique [Subtitling films. Technique. Aesthetics] (Unpublished manuscript), Paris.

Lambert, J. and van Gorp, H. (1985). On describing translations. In T. Hermans (Ed.), The manipulation of literature (pp. 42-53). New York: St Martin's Press.

Martí Ferriol, J.L. (2010). Cine independiente y traducción [Independent cinema and translation]. Valencia: Tirant lo Blanch.

Martí Ferriol, J.L. (2013). El método de traducción. Doblaje y subtitulación frente a frente [Translation mode. Dubbing and subtitling face to face]. Castelló de la Plana: Servei de Publicacions de la Universitat Jaume I. Col·lecció TRAMA.

Martínez Sierra, J.J. (2008). Humor y traducción. Los Simpson cruzan la frontera [Humour and translation. The Simpsons go abroad]]. Castelló de la Plana: Servei de Publicacions de la Universitat Jaume I.

Mason, I. (1989). Speaker meaning and reader meaning: preserving coherence in screen translating. In R. Kolmel \& J. Payne (Eds.), Babel. The cultural and linguistic barriers between nations (pp. 13-24). Aberdeen: Aberdeen University Press.

Mayoral, R., Kelly, D., \& Gallardo, N. (1986). Concepto de traducción subordinada (cómic, cine, canción, publicidad). Perspectivas no lingüísticas de la traducción (I) [The concept of 
subordinate translation (comic, cinema, song, advertising). Non-linguistic perspectives of translation (I)]. In F. Fernández (Ed.), Pasado, presente y futuro de la lingüística aplicada en España. Actas del III Congreso Nacional de Lingüística Aplicada (pp. 95-105). Valencia: Universitat de València.

Mayoral, R., Kelly, D., \& Gallardo, N. (1988). Concept of constrained translation. Non-linguistic perspectives of translation. Meta: Journal Des Traducteurs,33(3), 356. doi:10.7202/003608ar

Neves, J. (2005). Audiovisual translation: Subtitling for the deaf and the hard of hearing (Unpublished doctoral dissertation). The University of Roehampton: London.

Nornes, A. M. (1999). For an Abusive Subtitling. Film Quarterly, 52(3), 17-34.

O'Hagan, M., \& Sasamoto, R. (2016). Crazy Japanese subtitles? Shedding light on the impact of impact captions with a focus on research methodology. In S. Hansen-Schirra \& S. Grucza (Eds.) Eyetracking and Applied Linguistics (pp. 31-58). Berlin: Language Science Press.

Orrego-Carmona, D. (2015). The reception of (non)professional subtitling (Unpublished doctoral dissertation). Universitat Rovira i Virgili: Tarragona.

Pavesi, M. (2014) The Pavia Corpus of Film Dialogue: a means to several ends. In M. Pavesi, M. Formentelli \& E. Ghia (Eds.), The languages of dubbing: Mainstream audiovisual translation in Italy (pp. 29-55). Bern: Peter Lang.

Pérez-González, L. (2014). Audiovisual translation. Theories, methods and issues. London \& New York: Routledge.

Pérez-González, L. (2016). The politics of affect in activist amateur subtitling: A biopolitical perspective. In M. Baker and B. B. Blaagaard (Eds.), Citizen media and public spaces: Diverse expressions of citizenship and dissent (pp. 118-135). London \& New York: Routledge.

Pommier, C. (1988). Doublage et postsyncronisation. Paris: Dujarric.

Ragas, M., \& Roberts, M. (2009). Agenda setting and agenda melding in an age of horizontal and vertical media: A new theoretical lens for virtual brand communities. Journalism \& Mass Communication Quarterly, 86(1), 45-64.

Ranzato, I. (2016). Translating culture specific references on television. The case of dubbing. London \& New York: Routledge.

Richart Marset, M. (2012). Ideología y traducción. Por un análisis genético del doblaje [Ideology and translation. A genetic analysis of dubbing]. Madrid: Biblioteca Nueva

Richart Marset, M. (2015). La censura de la corrección política: la traducción audiovisual a escena. Quaderns de filologia. Estudis literaris, 20, 237-257.

Rojo, A., Ramos, M., \& Valenzuela, J. (2014). The emotional impact of translation: A hear rate study. Journal of Pragmatics, 71, 31-44.

Romero-Fresco, P. (2012). Accessible filmmaking: Joining the dots between audiovisual translation, accessibility and filmmaking. The Journal of Specialised Translation, 20, 201-223.

Saldanha, G., \& O’Brien, S. (2013). Research methodologies in translation studies. Manchester: St. Jerome.

Schäffner, C. (1998). The concept of norms in translation studies. Current Issues in Language and Society, 5(1-2), 1-9. 
Steinman, J. (1983). Total eclipse of the heart [Recorded by Bonnie Tyler]. On Faster than the speed of night [CD]. London, England: Columbia Records.

Titford, C. (1982). Subtitling-constrained translation. Lebende Sprachen, 27(3), 113-116.

Tymoczko, M. (2010). Translation, resistance, activism. Essays on the role of translators as agents of change. Amherst and Boston, MA: University of Massachusetts Press.

Valentini, C. (2006). A multimedia database for the training of audiovisual translators. Journal of Specialised Translation, 6, 68-84.

Villanueva Jordán, I., Hermoza Vega, F., \& Bravo Díaz, M. (2017). Experiencias profesionales y percepciones sobre la subtitulación interlingüística en Lima, Perú [Professional experiences and perceptions about interlinguistic subtitling in Lima, Peru]. Mutatis Mutandis, 10(2). Los estudios de traducción e interpretación en América Latina, 123-148.

Vöge, H. (1977). The translation of films, subtitling versus dubbing. Babel, 23(3), 120-125.

Wolf, M. \& Fukari, A. (2007). Constructing a sociology of translation. Amsterdam \& Philadelphia: John Benjamins.

Zanotti, S. (2018). Investigating the genesis of translated films: A view from the Stanley Kubrick Archive. Perspectives: Studies in Translation Theory and Practice, 26, 1-17. 